\title{
STRANGE BEDFELLOWS- PROSTATOMEGALY, CHOLELITHIASIS AND METABOLIC SYNDROME COMPONENTS- IS THERE A CORRELATION?
}

\author{
Rodriguez Mario Jose1, Sruthi Mankara Valson²
}

${ }^{1}$ Associate Professor, Department of Radiology, P. K. Das Institute of Medical Sciences, Ottapalam.

${ }^{2}$ Assistant Professor, Department of Community Medicine, P. K. Das Institute of Medical Sciences, Ottapalam.

\section{ABSTRACT}

\section{BACKGROUND}

As life expectancy goes up, a noticeable increase in ageing populations are seen in both developed as well as developing nations. Prostatic enlargement and cholelithiasis are important causes of morbidity in the elderly with attendant demands on health care delivery systems.

The aim of the study is to evaluate the frequency of urological and non-urological abnormalities on routine abdominal ultrasound scanning in patients with lower urinary tract symptoms and to determine if there is an association between the concomitant occurrence of prostatomegaly, cholelithiasis and components of the metabolic syndrome.

\section{MATERIALS AND METHODS}

Medical and ultrasound records of 509 male patients over the age of 40, who underwent abdominal ultrasonography for dyspeptic or lower urinary tract symptoms over a one-year period were analysed.

\section{RESULTS}

In 161 patients (31.6\%), prostatomegaly was detected; 58 patients (11.4\%) showed presence of cholelithiasis on ultrasound; 11 of those patients (18.9\%) showed associated prostatomegaly. Other urological abnormalities were detected in 85 patients (16.7\%) and in 8 patients (3.2\%) non-urological abnormalities were detected by ultrasonography. Urological conditions detected included hydronephrosis (12 pts.), renal cysts (18 pts.) and renal calculi (55 pts.). Non-urological conditions included fatty liver (48 pts.), pancreatitis (4 pts.), splenomegaly (4 pts.); 86 out of 233 patients (36.8\%) with diabetes mellitus, 90 out of 205 (43.9\%) with hypertension and 58 out of $158(36.7 \%)$ with hypercholesterolaemia also showed prostatomegaly on their ultrasound scan.

\section{CONCLUSION}

Prostatomegaly shows statistically significant associations with ultrasound of genitourinary system findings namely hydronephrosis, renal calculi and renal cortical cysts. Two non-urological conditions which were significantly associated with prostatomegaly were fatty liver and cholelithiasis. Strong associations are noted between diabetes mellitus, hypertension and hypercholesterolaemia and the presence of prostatomegaly.

\section{KEYWORDS}

Prostatomegaly, Cholelithiasis, Co-Morbidities, Ultrasound Scanning.

HOW TO CITE THIS ARTICLE: Jose RM, Valson SM. Strange bedfellows- prostatomegaly, cholelithiasis and metabolic syndrome components- is there a correlation? J. Evolution Med. Dent. Sci. 2017;6(69):4930-4933, DOI: 10.14260/Jemds/2017/1069

\section{BACKGROUND}

At first glance prostatomegaly and cholelithiasis appear to be an odd clinical pairing, given the marked preponderance of cholelithiasis in female subjects. However, observation of an association of the two conditions in routine ultrasound scanning of hospital patients suggests a correlation between the two. The present study looks at ultrasound data obtained from scans done at a multispeciality hospital over a one-year period to determine if there exists a correlation between the two entities.

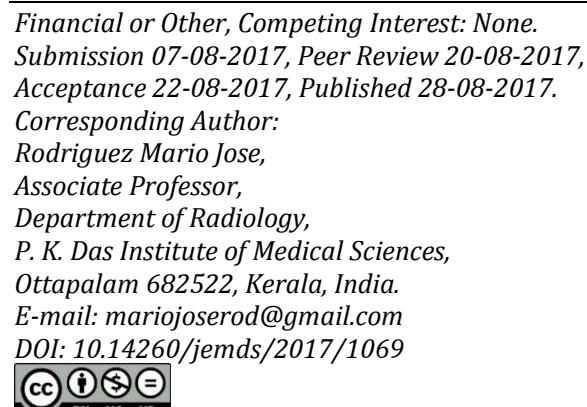

\section{Aim and Objectives}

The study aims to compare incidence of cholelithiasis and prostatomegaly occurring individually and together in adult males over the age of 40, and to establish if there exists any correlation between the two, and to examine possible association between the occurrence of prostatomegaly in conjunction with components of metabolic syndrome.

\section{MATERIALS AND METHODS Study Design \\ Hospital based cross-sectional study.}

\section{Study Period}

Patients in the study group undergoing abdominal ultrasound in a 1 year period from Jan 2015 - Jan 2016.

\section{Study Subjects}

Adult males aged 40 years or above undergoing ultrasound scans in a semi-urban hospital setting in Kerala.

\section{Sample Size Calculation}

From previous study done by Basawaraj $\mathrm{NG}^{1}$ from South India, the prevalence of prostatomegaly in ultrasonography is 
$19.8 \%$. Using the formulae $4 \mathrm{PQ} / \mathrm{d}^{2}$, taking $\mathrm{P}$ as $19.8 \%, \mathrm{Q}$ as $100-19.8=80.2$ and $\mathrm{d}$ as $20 \%$ of $\mathrm{P}$, the calculated minimum sample size was 405 . The consecutive sampling method is used and 509 males came for abdominal ultrasound examination were included in the study.

\section{Inclusion Criteria}

- Adult male outpatients aged 40 years and above presenting with abdominal pain/dyspepsia, abdominal distension or lower urinary tract symptoms (LUTS).

\section{Exclusion Criteria}

- Hospitalised patients.

- Patients with previous history of prostatic or gall bladder surgery.

- Patients with abdominal masses.

- Patients with previous clinical or ultrasound features of either acute cholecystitis or prostatitis.

\section{Study Procedure}

From each patient data regarding age, symptomatology and co-morbidities was collected from hospital records. Abdominal ultrasonography was done for all subjects in a fasting state after oral hydration and a normally distended urinary bladder with special reference to gall bladder and prostatic status. Prostatic size is estimated by a computed calculation of cross-sectional diameter $\mathrm{x}$ height $\mathrm{x}$ craniocaudal span x 0.52. Gallstones were defined as the presence of strong intraluminal echoes that were gravity dependent and/or that attenuated ultrasound transmission (acoustic shadowing).

\section{Statistical Analysis}

Data was coded and entered in Microsoft Excel. The whole data was rechecked and analysed using statistical software SPSS version 16 . The various urological and non-urological findings in ultrasonography were expressed in rate and percentages. The Pearson chi-square test was used to find out the association between co-morbidities and prostatomegaly and cholelithiasis. If the expected count of any one cell is less than 5, Fisher's exact test was used. The level of significance was estimated with $95 \%$ confidence interval with a $\mathrm{p}$ value < 0.05 .

\section{RESULTS}

\section{Age Distribution of Study Population}

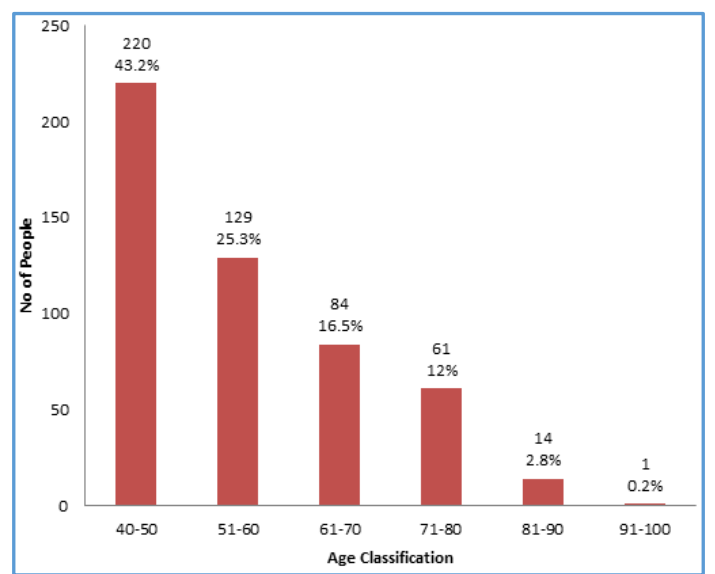

In the present study, majority of $220(43.2 \%)$ patients belonged to age group 40 - 50 followed by age group $51-60$ 129 (25.3\%), 61 - 7084 (16.5\%), 71 - 8061 (12\%), 91 - 1001 $(0.2 \%)$ respectively. The mean age of study population is $55.54+12.55$. It ranges from 40 to 92 .

Prevalence of Prostatomegaly among Study Population Aged more than 40 yrs.

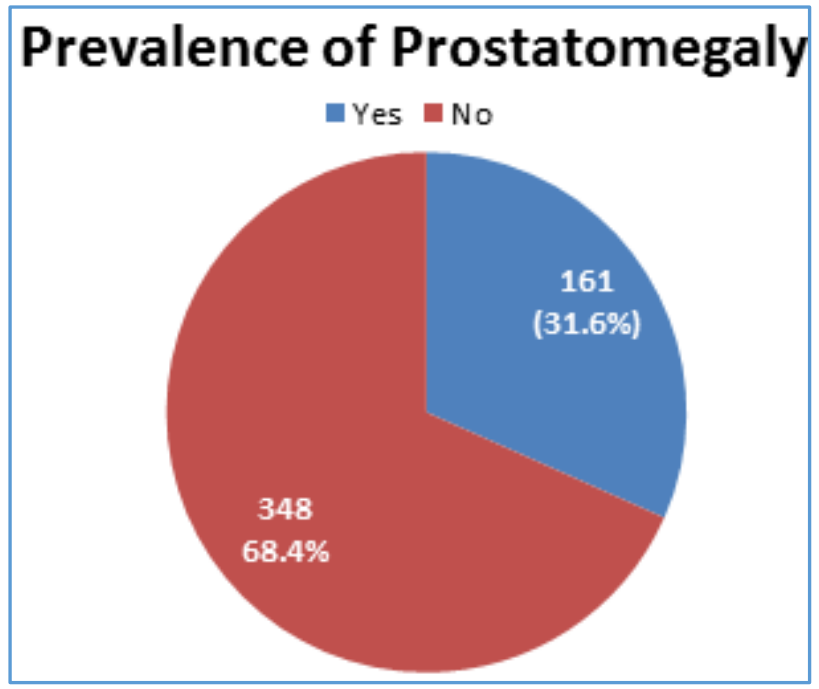

The present study shows that $161(31.6 \%)$ adults aged more than 40 had prostatomegaly on USG investigation.

Distribution of Study Population according to Grading of Prostatomegaly

\section{Grading of Prostatomegaly}

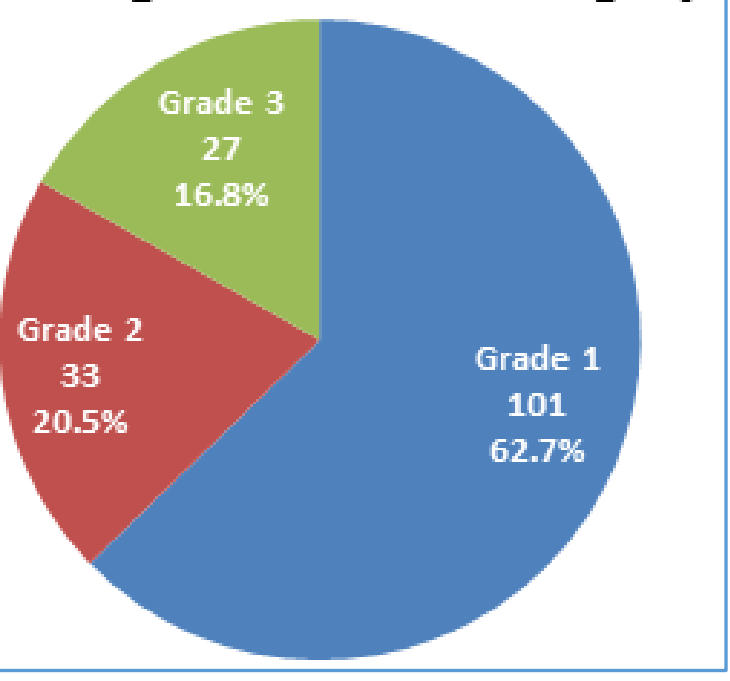

Out of total 161 individuals who had prostatomegaly, 101 $(62.7 \%)$ had grade 1 prostatomegaly, $33(20.5 \%)$ had grade 2 prostatomegaly and $27(16.8 \%)$ had grade 3 prostatomegaly. The severity of prostatic enlargement correlated well with advancing patient's age. PSA investigation was done for grade 3 prostatomegaly and it was found to be significantly elevated in 11 patients. 
Prevalence of Cholelithiasis among Adults Aged more than 40 yrs.

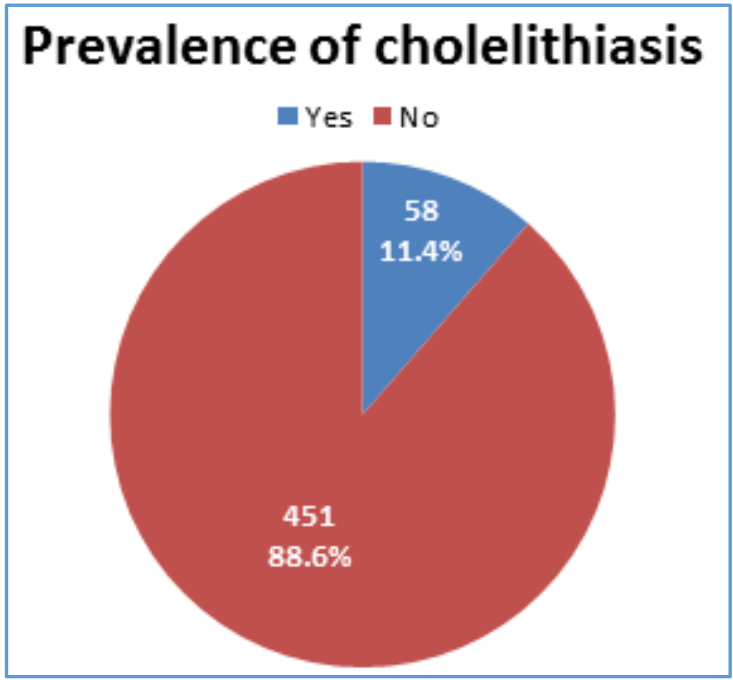

In this study out of total 509 adults, 58 (11.4\%) of individuals had cholelithiasis on USG.

$11(18.9 \%)$ of these subjects had cholelithiasis with concomitant prostatomegaly.

Prevalence of other Diagnoses on USG among Study Population

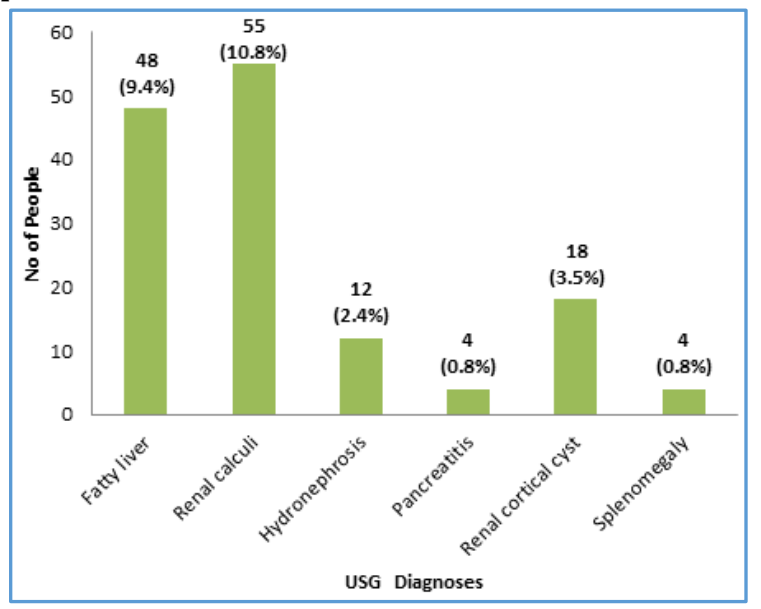

Distribution of Study Population according to CoMorbidities

\begin{tabular}{|c|c|c|c|c|}
\hline Sl. & Particulars & $\begin{array}{c}\text { Classifi- } \\
\text { cation }\end{array}$ & $\begin{array}{c}\text { No. } \\
\text { Total - 509 }\end{array}$ & \% \\
\hline \multirow{2}{*}{ 1. } & \multirow{2}{*}{ Diabetes Mellitus } & Yes & 233 & $45.77 \%$ \\
\cline { 3 - 5 } & No & 276 & $54.23 \%$ \\
\hline \multirow{2}{*}{2.} & Hypertension & Yes & 205 & $40.27 \%$ \\
\cline { 3 - 5 } & No & 304 & $59.73 \%$ \\
\hline \multirow{2}{*}{3.} & $\begin{array}{c}\text { Both Hypertension } \\
\text { and DM }\end{array}$ & Yes & 89 & $17.48 \%$ \\
\cline { 3 - 5 } 4. & $\begin{array}{c}\text { Hyper- } \\
\text { cholesterolaemia }\end{array}$ & Yes & 420 & $82.52 \%$ \\
\hline & & No & 351 & $31 \%$ \\
\hline
\end{tabular}

In the present study $233(45.77 \%)$ of individuals had Diabetes mellitus, 205 (40.27\%) had hypertension, 158 (31\%) had hypercholesterolaemia and 89 (17.48\%) had both hypertension and diabetes.
Association between USG Diagnoses and Prostatomegaly

\begin{tabular}{|c|c|c|c|c|c|}
\hline \multirow[b]{2}{*}{ Particulars } & \multirow[b]{2}{*}{$\begin{array}{l}\text { Classifi- } \\
\text { cation }\end{array}$} & \multicolumn{2}{|c|}{ Prostatomegaly } & \multirow[b]{2}{*}{ Total } & \multirow[b]{2}{*}{$\begin{array}{c}P \\
\text { value }\end{array}$} \\
\hline & & $\begin{array}{c}\text { Yes } \\
(161)\end{array}$ & $\begin{array}{c}\text { No } \\
\text { (348) }\end{array}$ & & \\
\hline \multirow{2}{*}{ Cholelithiasis } & Yes & 11 & 47 & 58 & \multirow{2}{*}{$<0.01$} \\
\hline & No & 150 & 301 & 451 & \\
\hline \multirow{2}{*}{ Fatty liver } & Yes & 42 & 6 & 48 & \multirow{2}{*}{$<0.001$} \\
\hline & No & 119 & 342 & 461 & \\
\hline \multirow{2}{*}{ Renal calculi } & Yes & 53 & 2 & 55 & \multirow{2}{*}{$<0.001$} \\
\hline & No & 108 & 346 & 454 & \\
\hline \multirow{2}{*}{ Hydronephrosis } & Yes & 29 & 4 & 33 & \multirow{2}{*}{$<0.001$} \\
\hline & No & 132 & 344 & 476 & \\
\hline \multirow{2}{*}{ Pancreatitis } & Yes & 2 & 2 & 4 & \multirow{2}{*}{0.58} \\
\hline & No & 159 & 346 & 505 & \\
\hline \multirow{2}{*}{$\begin{array}{c}\text { Renal cortical } \\
\text { cyst }\end{array}$} & Yes & 17 & 1 & 18 & \multirow{2}{*}{$<0.001$} \\
\hline & No & 144 & 347 & 491 & \\
\hline \multirow{2}{*}{ Splenomegaly } & Yes & 1 & 3 & 4 & \multirow{2}{*}{0.77} \\
\hline & No & 160 & 345 & 505 & \\
\hline
\end{tabular}

$P$ value $<0.05$ - significant

The present study shows statistically significant association between prostatomegaly and cholelithiasis, fatty liver, bilateral renal calculi, hydronephrosis and renal cortical cysts ( $\mathrm{p}$ value $-<0.01$ ).

Association between Prostatomegaly and Co-Morbidities

\begin{tabular}{|c|c|c|c|c|c|}
\hline \multirow{2}{*}{ Particulars } & \multirow{2}{*}{ Classification } & \multicolumn{2}{|c|}{$\begin{array}{l}\text { Diabetes } \\
\text { Mellitus }\end{array}$} & \multirow{2}{*}{ Total } & \multirow{2}{*}{$\begin{array}{c}\mathbf{P} \\
\text { value }\end{array}$} \\
\hline & & $\begin{array}{l}\text { Yes } \\
(233)\end{array}$ & $\begin{array}{c}\text { No } \\
(276)\end{array}$ & & \\
\hline \multirow{2}{*}{$\begin{array}{l}\text { Prostato- } \\
\text { megaly }\end{array}$} & Yes & 86 & 75 & 161 & \multirow[b]{2}{*}{0.02} \\
\hline & No & 147 & 201 & 348 & \\
\hline \multirow{4}{*}{$\begin{array}{l}\text { Prostato- } \\
\text { megaly }\end{array}$} & & \multicolumn{2}{|c|}{ Hypertension } & & \multirow{4}{*}{$<0.001$} \\
\hline & & Yes (205) & No (304) & & \\
\hline & Yes & 90 & 71 & 161 & \\
\hline & No & 115 & 233 & 348 & \\
\hline \multirow{4}{*}{$\begin{array}{l}\text { Prostato- } \\
\text { megaly }\end{array}$} & & \multicolumn{2}{|c|}{$\begin{array}{c}\text { Hyper- } \\
\text { cholesterolaemia }\end{array}$} & & \multirow{4}{*}{0.04} \\
\hline & & Yes (158) & No (351) & & \\
\hline & Yes & 52 & 109 & 161 & \\
\hline & No & 106 & 242 & 348 & \\
\hline
\end{tabular}

$P$ value $<0.05-$ significant

There is a statistically significant difference between prostatomegaly and diabetes mellitus.

( $\mathrm{P}$ value- 0.02), prostatomegaly and hypertension ( $\mathrm{p}$ value- $<0.001$ ), and prostatomegaly and cholelithiasis ( $p$ value- 0.04).

Association between Cholelithiasis and Co-Morbidities

\begin{tabular}{|c|c|c|c|c|c|}
\hline \multirow{2}{*}{ Particulars } & \multirow{2}{*}{ Classification } & \multicolumn{2}{|c|}{$\begin{array}{l}\text { Diabetes } \\
\text { Mellitus }\end{array}$} & \multirow{2}{*}{ Total } & \multirow{2}{*}{$\begin{array}{c}P \\
\text { value }\end{array}$} \\
\hline & & $\begin{array}{c}\text { Yes } \\
(233)\end{array}$ & $\begin{array}{c}\text { No } \\
(276)\end{array}$ & & \\
\hline \multirow{2}{*}{ Cholelithiasis } & Yes & 33 & 25 & 58 & \multirow{2}{*}{0.04} \\
\hline & No & 200 & 251 & 451 & \\
\hline \multirow{4}{*}{ Cholelithiasis } & & Hype & ension & & \multirow{4}{*}{0.01} \\
\hline & & Yes (205) & No (304) & & \\
\hline & Yes & 32 & 26 & 58 & \\
\hline & No & 173 & 278 & 451 & \\
\hline \multirow{4}{*}{ Cholelithiasis } & & \multicolumn{2}{|c|}{$\begin{array}{c}\text { Hyper- } \\
\text { cholesterolaemia }\end{array}$} & & \multirow{4}{*}{0.04} \\
\hline & & \begin{tabular}{|l|} 
Yes (158) \\
\end{tabular} & No (351) & & \\
\hline & Yes & 22 & 36 & 58 & \\
\hline & No & 136 & 315 & 451 & \\
\hline
\end{tabular}

$P$ value $<0.05$ - significant 
The statistically significant difference was obtained between cholelithiasis and hypertension, cholelithiasis and diabetes mellitus, cholelithiasis and hypercholesterolaemia ( $p$ value $<0.05)$.

\section{DISCUSSION}

Cholelithiasis and prostatomegaly are common conditions in aging populations worldwide. Due to their high prevalence and elevated cost of treatment, they are important conditions for which further research is needed. Few articles exist in published literature regarding the association of cholelithiasis with prostatic enlargement.(2-4) Gallstones and prostatomegaly share common risk factors namely advancing age, obesity, insulin resistance and diabetes, and genetic predisposition. (5-9) Our evaluation showed comparable rates of co-morbidities in patients compared to a large Asian multinational study.(10) It may be postulated that there is a direct link between these conditions. Earlier studies referred to above shows $(3,4)$ approximately $3 \%-4 \%$ of patients with prostatomegaly having incidentally detected cholelithiasis. Our study shows a rate of $18.9 \%$ of patients sharing both diagnoses. It would seem that there are other aetiologic factors at work and there is reason for further study of this phenomenon.

\section{CONCLUSION}

In summary, benign prostatic hyperplasia shows close association with other findings relatable to the genitourinary system namely hydronephrosis, renal calculi and renal cortical cysts. Two conditions outside the genitourinary system which were significantly associated with prostatomegaly were fatty liver and cholelithiasis. Both cholelithiasis and prostatomegaly had close association with components of the metabolic syndrome namely diabetes mellitus, hypertension and hypercholesterolaemia.

\section{REFERENCES}

[1] Basawaraj NG, Dasan TA, Patil SS. Correlation of sonographic prostate volume with international prostate symptom score in South Indian men. Int J Res Med Sci 2015;3(11):3126-30.

[2] Bhattarai MD. Re: general surgery units, asymptomatic gallstones and benign prostatic hypertrophy. Surgeon 2003;1(6):361.

[3] Al-Durazi MH, Al-Helo HA, Al-Reefi SM, et al. Routine ultrasound in acute retention of urine. Saudi Med J 2003;24(4):373-5.

[4] Rafique M. Value of routine renal and abdominal ultrasonography in patients undergoing prostatectomy. Int Urol Nephrol 2006;38(1):153-6.

[5] Parsons JK. Lifestyle factors, benign prostatic hyperplasia, and lower urinary tract symptoms. Curr Opin Urol 2011;21(1):1-4.

[6] Park YW, Kim SB, Kwon H, et al. The relationship between lower urinary tract symptoms/benign prostatic hyperplasia and the number of components of metabolic syndrome. Urology 2013;82(3):674-9.

[7] Bennion LJ, Grundy SM. Risk factors for the development of cholelithiasis in man. N Engl J Med 1978;299:1161-7.

[8] Bennion LJ, Grundy SM. Risk factors for the development of cholelithiasis in man (second of two parts). N Engl J Med 1978;299(22):1221-7.

[9] Sanda MG, Beaty TH, Stutzman RE, et al. Genetic susceptibility of benign prostatic hyperplasia. J Urol 1994;152(1):115-9.

[10] Li MK, Garcia L, Patron N, et al. An Asian multinational prospective observational registry of patients with benign prostatic hyperplasia, with a focus on comorbidities, lower urinary tract symptoms and sexual function. BJU Int 2008;101(2):197-202. 